Article

\title{
Integrating Water Sensitive Design in the Architectural Design Studio in China: Challenges and Outcomes
}

\author{
Maycon Sedrez ${ }^{1, *(\mathbb{D})}$, Jing Xie ${ }^{1}$ and Ali Cheshmehzangi ${ }^{1,2}$ (D) \\ 1 Centre for Sustainable Energy Technologies, Department of Architecture and Built Environment, University \\ of Nottingham, Ningbo 315100, China; jing.xie@nottingham.edu.cn (J.X.); \\ ali.cheshmehzangi@nottingham.edu.cn (A.C.) \\ 2 Network for Education and Research on Peace and Sustainability (NERPS), Hiroshima University, \\ Hiroshima 739-8530, Japan \\ * Correspondence: maycon.sedrez@nottingham.edu.cn
}

check for updates

Citation: Sedrez, M.; Xie, J.; Cheshmehzangi, A. Integrating Water Sensitive Design in the Architectural Design Studio in China: Challenges and Outcomes. Sustainability 2021, 13, 4853. https://doi.org/10.3390/ su13094853

\section{Academic Editors: Rosa}

Schiano-Phan and Gonclaves Joana Carla Soares

Received: 5 March 2021

Accepted: 23 April 2021

Published: 26 April 2021

Publisher's Note: MDPI stays neutral with regard to jurisdictional claims in published maps and institutional affiliations.

Copyright: (c) 2021 by the authors. Licensee MDPI, Basel, Switzerland. This article is an open access article distributed under the terms and conditions of the Creative Commons Attribution (CC BY) license (https:// creativecommons.org/licenses/by/ $4.0 /)$.

\begin{abstract}
Urban areas around the world are increasingly facing environmental challenges such as water scarcity, water pollution, and water-related disasters, which demands sustainable design solutions for cities. Efforts to introduce sustainable methods in architectural education are noteworthy since the early 1990s. However, Water Sensitive Design (WSD) has not been fully integrated to architectural education. WSD is an interdisciplinary approach that considers the water cycle as the primary element of design strategies, integrating the site's ecological and social aspects to structure water management. The main objective of this study is to identify cases introducing WSD in an architecture design studio revealing its pedagogical approaches, comparing and discussing with a WSD-focused design studio. This study adapts on an exploratory and descriptive research, analyzing the literature on the topic of WSD in architectural education and documenting a graduate-level architectural design studio that proposes the development of water-oriented masterplan. The results suggest that WSD, as interdisciplinary method, can be incorporated into the design studio as the topic due to its tangible tools and strategies towards water. It also fits the proposal of a design studio to integrate knowledge from diverse disciplines. This unique study presents a comprehensive WSD introduction in an architectural design case and indicative pedagogical methods, contributing to the development of an approach for future related works.
\end{abstract}

Keywords: Water Sensitive Urban Design; Water Sensitive Design; architectural education; architecture and urban design; teaching methods

\section{Introduction}

Water is essential for human and wildlife survival and performs an important role on cities' functionality [1,2]. The expanding and unthoughtful consumption of water, in combination with climate change and environmental pollution is causing major implications for cities. Today, according to the United Nations (UN), "3.6 billion people (nearly half of the global population) live in areas that are potential water-scarce at least one month per year" [3]. Furthermore, increasing challenges such as water scarcity, water pollution, and water-related disasters must be considered as one of the top priorities in architectural and urban design. Furthermore, sustainability is considered a key topic to be integrated in architecture design studios [4], requiring tutors to rethink studio approaches. The UN suggests significant data concerning contemporary water issues: "floods and other water-related disasters account for $70 \%$ of all deaths related to natural disasters", "water scarcity affects more than $40 \%$ of the global population", and "more than $60 \%$ of wastewater resulting from human activities is discharged into rivers or sea without any pollution removal" [5]. The UN also proposes a specific agenda for water and development-recognizing the urgency of holistic and sustainable solutions for water resources in several scales-the so-called Sustainable Development Goal Six-SDG6: Clean Water and Sanitation. 
Water Sensitive Urban Design (WSUD), Low Impact Development (LID), Water Sensitive Cities (WSC), Sponge City Program (SCP), Green Infrastructure (GI), Sustainable Urban Drainage Systems (SUDS) are terms and programs that originated in different countries and present sets of strategies to manage urban water systems. They share common aspects, have similar characteristics, and became ubiquitous in recent decades. These strategies include urban design approaches and solutions, plus recommendations for regulations, policies, and implementation. WSUD originated in Australia and developed broader objectives concerning water management, consisting of higher applicability from the architecture point of view. Figure 1 below highlights an example of urban drainage terminology classification [6], which puts together the terms and programs in relation to specific techniques, concepts, and broad principles.

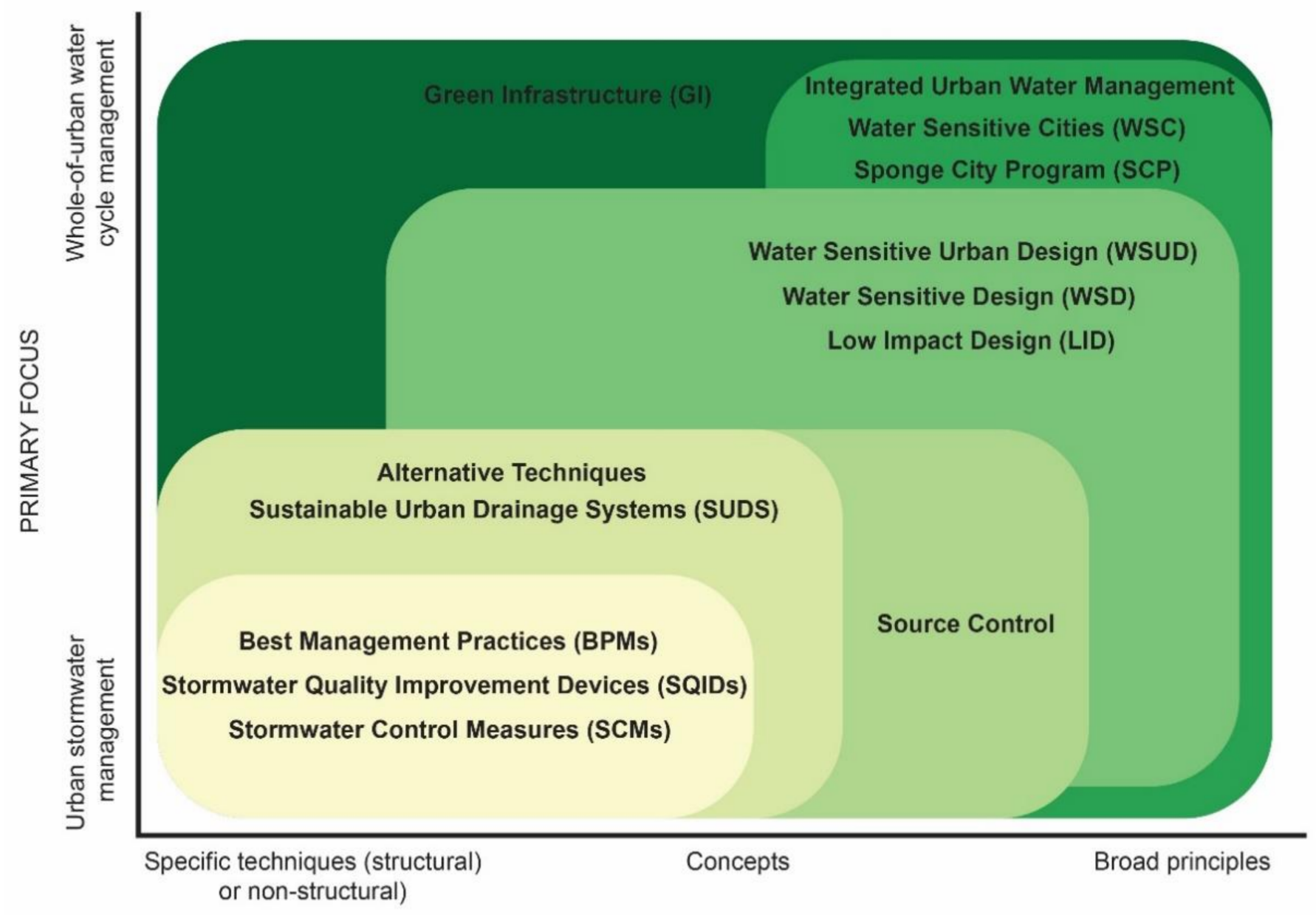

\section{SPECIFICITY}

Figure 1. Urban drainage terminology, drawn by the authors adapted from Fletcher et al. [6].

Water Sensitive Urban Design (WSUD) provides technical solutions for management of stormwater [1], improving the city ecosystem by reducing water pollution, mitigating urban heat island, and improving water supply. Such methods were introduced in urban planning and design practices to respond to the challenges faced by cities and previously described. WSUD requires interdisciplinary integration to allow designs that create waterresponsive urban spaces, it tackles technical, environmental, and social interactions; thus, architects, urbanists, landscape designers, engineers, and ecologists can develop and test solutions collaboratively and in an integrated method. WSUD deals with inefficiencies of active hidden urban water systems (pipes that collect and conduct) when it comes to stormwater events, aiming more passive, visible, and natural solutions (filtering, cleaning, 
absorbing, evaporating, and accumulating). It seeks solutions to reduce pollution of water sources and increase volumes of fresh water sources [7]. WSUD strategies achieve better results in projects that take in consideration the natural water cycle key aspects: high evaporation, high rate of infiltration, and low surface runoff [1]. These aspects come aligned with new ecological views for cities resultant of introduction of interdisciplinary methods in the architecture, urbanism, and planning.

WSUD proposes high-tech and low-tech strategies to manage water in urban environments, however, the integration in architectural design might be neglected by urban designers due to the high level of engineering and technical knowledge in certain aspects. Yet, WSUD is based on technologies and research on water management that are known for several decades and centuries. Although WSUD has been applied in design practice [1] and related WSUD projects have been assessed [8], its application in architectural education is scarce. A literature review is presented in chapter 3 documenting the cases of WSUD in architectural design studios. This study advocates for a broader more inclusive term: Water Sensitive Design (WSD), since it consolidates three scales of application: architecture, urbanism, and landscape. WSD is an interdisciplinary approach that considers the water cycle as the primary element of design strategies, integrating the site's ecological and social aspects to structure water management from building to city scale. Therefore, the application of WSD in architecture and urban design learning is key for successful plans and development of sustainable designs.

The demand for architecture graduated professionals with knowledge about water strategies for sustainable cities has increased in China due to the implementation and expansion of the SCP in many cities. Introduced in 2013 and then initiated in 2015, the Chinese government, involving the three main ministries of Finance, Housing and UrbanRural and Development, and Water Resources "aimed at addressing urban flooding and waterlogging" $[9,10]$. The program is recognized as a national plan to "adopt successful practices of stormwater management and to resolve the local environmental problems" [11]. Since the start of the program, there are many pilot projects across the country, some already completing the experimental phases and towards scaling up processes. In most cases, the program has been implemented in natural areas inside cities, new developments, or interventions around heritage sites. Early projects include the urban renovation of the Olympic Village in Beijing [12], in Suzhou historical Town of Luzhi [13], and the SCP in the City of Ningbo [10].

This study presents and analyzes the integration of WSD in an architectural design studio through master planning for a waterfront site in Ningbo, a coastal city in east China. The introduction of sustainable challenges in architectural education is reported by Altomonte as emergent and needed [4]. The main objective of this study is to identify cases introducing WSD in an architecture design studio, revealing its pedagogical approaches, comparing and discussing with a WSD-focused design studio. This study also presents the challenges and limitations faced by teaching team and students, identifying identify potential points that facilitate and leverage WSD strategies in learning for future activities.

\section{Materials and Methods}

The methodological framework of the study is divided into four parts. First, the study benefits from a literature review, which involves mapping the existing literature related to the water-sensitive design and teaching nexus. In doing so, a specific stream for architecture design studio teaching is selected, mainly highlighting the comprehensiveness of the selected topic and its relevance to architectural design education. In the second step, the study goes through a set of evaluations including the assessment of (1) existing practices for teaching and learning in relevant areas, (2) defining a pedagogical approach, and (3) reflecting on specific learning outcomes embedded in the program. Then, the concepts are integrated into the studio teaching, first through the studio theme, then the student project work in the design studio unit, and the pedagogical understanding of the integrated concepts in teaching. Here, the pedagogical aspects include the study area of 
the project, including its size and location, specific project requirements, and the theme of the study. As part of this study, 32 students (in one design studio unit) were involved in two cohorts of a third year and final year undergraduate program in architecture. The duration of the project was eight months, including two academic semesters. The team involved in this pedagogical study included two full-time teaching staff and one part-time staff, including two senior and one junior members, with at least three years of teaching experience. Following the integration and pedagogical work, the study suggests three sets of findings in the last stage of the methodological framework. These include a detailed understanding of the lack of materials in teaching, recognizing and valuing the knowledge of topics generated for teaching from the perspective of WSD-Sustainability research in the architecture design studio teaching, and pedagogical suggestions relevant to the future work. The steps are summarized in Figure 2 below.

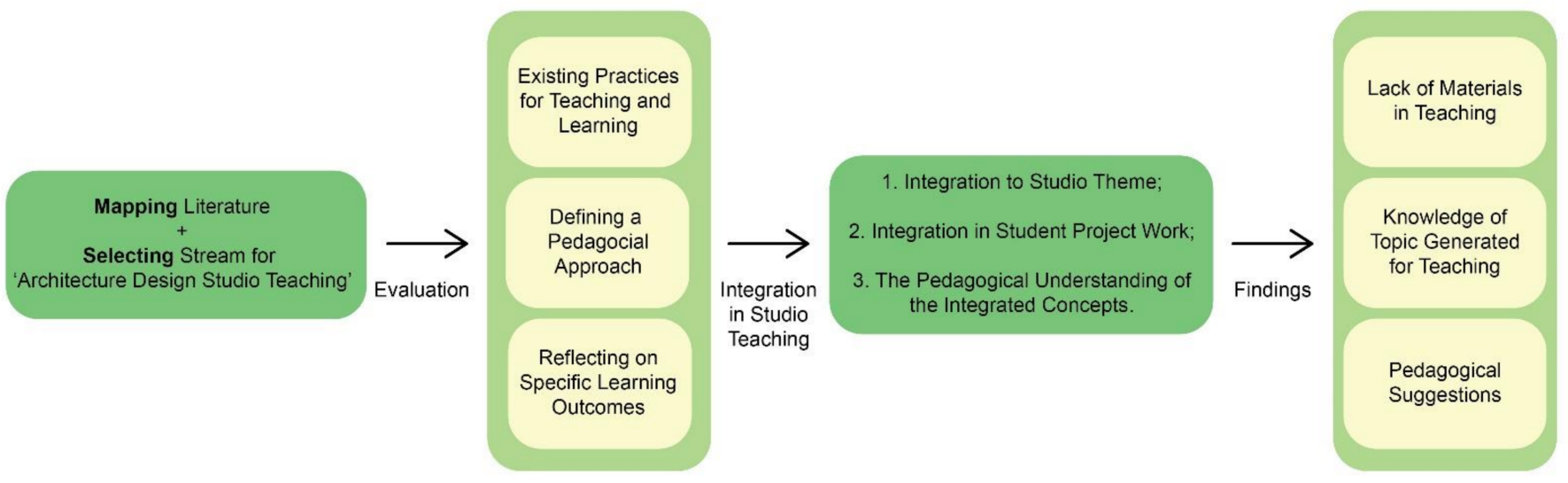

Figure 2. Methodological framework. Source: authors.

By employing exploratory and descriptive methods, this study analyzes the literature on the topic of WSD in architecture and documents a teaching and learning process from an architectural design studio that proposes water-conscious design as the main guideline. The studio was organized in three groups having interactions with tutors two days per week for five weeks. A set of WSD references were provided to students, as well as specific tutorials and lectures. The tutors actively instructed and collaborated with students towards implementation of WSD strategies. The full architecture design studio structure is explained in the following chapters.

This study focuses on the terms WSD and WSUD due to its broader objectives, for instance, manage the water cycle, which can be resolved with creative solutions. Therefore, it is extremely useful and applicable for architecture design studios and practices. WSD was selected as the architecture design studio theme to facilitate the understanding of its concepts by undergraduate students. The main intention was to enable students to consider such strategies in their design process and implement relevant techniques for water-sensitive design. To put together a comprehensive literature review of WSD in architectural education, we map various approaches used by other academics to gather information. The literature review also highlights comparative samples searched from multiple sources. The goal is to determine the pedagogical methods applied and discuss the results of such studios. The review studies are extracted from available scientific databases (i.e., Google Scholar, Science Direct, and JSTOR) until January 2020. These are recognized as the main sources of databased documentation in the field and provide a comprehensive overview of the topic and its multiple approaches. In this review, the terms 'Water Sensitive Design' and 'Water Sensitive Urban Design' plus 'AND pedagogy', 'AND teaching', 'AND studio', and 'AND "architectural design"' were searched separately in the selected scientific databases (Table 1). 
Table 1. Review of WSD and WSUD in scientific databases until January 2020. Source: authors.

\begin{tabular}{ccccccc}
\hline & \multicolumn{2}{c}{ Google Scholar $^{\mathbf{1}}$} & \multicolumn{2}{c}{ Science $^{\text {Direct }}{ }^{2}$} & \multicolumn{2}{c}{ Jstor $^{3}$} \\
\hline Searched Terms & WSD & WSUD & WSD & WSUD & WSD & WSUD \\
\hline AND pedagogy & 13 & 87 & 0 & 1 & 0 & 1 \\
AND teaching & 119 & 3340 & 1 & 9 & 0 & 4 \\
AND studio & 60 & 367 & 0 & 8 & 3 & 7 \\
AND “architectural design" & 39 & 255 & 0 & 10 & 1 & 3 \\
Total & 231 & 4049 & 1 & 28 & 4 & 15 \\
\hline
\end{tabular}

${ }^{1}$ Excluding patents and citations; a detailed search was done until 5th page (10 results per page); ${ }^{2}$ Advanced search; only researched articles, book chapters, and conferences abstracts; ${ }^{3}$ Advanced search; only articles.

Although the quantity of returns from the Google Scholar database is significantly higher than the other two scientific databases, Google Scholar results are not always scientific papers, they can be duplicated (for instance, book chapters), have low significance for this study, or do not really tackle the WSD in architectural education. A set of documents is then selected and referred throughout this study. Only a single article specifically dealt with WSD in architectural education, an aspect highlighted by Blagojevic [14]. In addition, we searched the academic publication archives from Cooperative Research Centre (CRC) for Water Sensitive Cities, using the terms 'Water Sensitive Design', finding 34 papers [15]; none of them dealing with the subject on education.

Secondly, having an overview of WSD in architectural and urban design, we describe an experience of introducing WSD in an architectural design studio and analyze the resultant masterplans for a waterfront site. The studio was offered to students from year 3 and 4 of architecture and was conducted as a vertical design. These two research methods (literature review and case study_pedagogical aspects) contributed to building an approach of WSD in architectural education and give significance to the topic. In this study, rainwater refers to water collected directly from roofs, canopies, and architecture or landscape structures designed for that purpose. Stormwater, on the other hand, represents water drained from the ground, which is contaminated by particles of soil, dust, and other elements found in the urban environments.

\section{Literature Review}

\subsection{Water Sensitive Design}

An extensive WSUD literature review is organized by Hoyer et al. [1] and Sharma et al. [16]. This brief review, presented here, highlights key aspects of WSD that are meaningful for architectural education. A basic principle of WSD is the promotion of sustainable design solutions to rebalance the water cycle in cities. These solutions range from simple (low-tech, small, and mid-size scale) to complex (high-tech, large scale) and achieve better results when they are considered in the first design phase, as stated by Hoyer et al. [1] (p. 3.8): "WSUD principles are most effective and economical when integrated into development design at the concept design stage".

With an improved understanding of water cycle, WSD has evolved from water management methods since the 2000s [6,16-18]. However, it can be considered as a universal concept under different nomenclatures, such as Low Impact Development (LID), Water Sensitive Cities (WSC), or Green Infrastructure (GI) to name a few [17]. In fact, Fletcher et al. studied the evolution of different terms in order to facilitate communication between related fields, highlighting its emergence in the 1980s [6]. In addition, Radcliffe understands the terms around the world in a historical perspective [17], indicating their relevance in policy and practices. These approaches have common features that are being recognized, but their application depends on the context and political organization. WSUD has broader principles, and they are less specific techniques compared to other terms [6]; this can be a supportive aspect of creativity in architecture design studio. As a new science field, WSD is interdisciplinary and integrates water management, architectural and urban design, and landscape planning, which will guide the projects to be "ecological, economical, social 
and cultural sustainability" [1]. By emphasizing the management of the water cycle in the whole design process (conceptual to implementation), architects can raise the sustainable level of a place and deliver suitable urban projects. The social aspects of WSD are highlighted by Hoyer et al. [1] and Visconti [19], including its capacity of generating urban spaces that are aesthetically pleasing and engaging.

WSUD is considered "an approach to urban planning and design" [7]. In Australia, WSUD is oriented towards solutions for dry weather conditions and explores opportunities to harvest stormwater, while in China, the approaches developed for the Sponge City Program (SPC) are based on LID or Sustainable Urban Drainage Systems (SUDS), from the United States of America and the United Kingdom, respectively. Additionally, in China, a focus of projects has been on "harvesting stormwater or environmental protection" [11]. Water Sensitive Urban Design is a specific term that contains a set of strategies for urban spaces [20], dealing with management of wastewater, stormwater, and water recycle systems [8]. Water Sensitive Design is a broader term that includes a set of strategies for urban design, landscape design, and architectural design, strategies derived from WSUD, SUDS, LID, GI, encompassing various scales of intervention. A detailed correlation between terms is discussed by Fletcher et al. [6], for the purposes of this study, WSD provides an inclusive view of the topic.

\subsection{WSD Strategies}

There are four WSD principles: (1) less potable water demand (use rainwater, reuse wastewater); (2) reduce wastewater generation; (3) treat stormwater; (4) use natural water occurrences as landscape element [18]. In terms of technical solutions, basically WSD offers strategies to accumulate rainwater, to filter rainwater, and finally to discharge water back into nature, but WSD also connects social and technological aspects. These solutions can be achieved by natural components of landscape (gardens, pools), by technological approaches (pipes, roofs, pumps), or by a combination of both (reservoirs, tanks). It is important to note that some solutions have been already applied in architecture for many centuries, for instance, patio with water cistern for cooling and reserving water, others were recently optimized, such as green roofs (also found in millenary architectures).

The manual created by the Department of Planning and Local Government-DPLG [7] to explain main tools adopted in Adelaide, Australia, indicates the following WSD strategies: demand reduction; rainwater tanks; rainwater gardens, green roofs, and infiltration systems; pervious pavements; urban water harvesting and reuse; gross pollutant traps; bioretention systems for streetscapes; swales and buffer strips; sedimentation basins; constructed wetlands; wastewater management. Effective WSD plans must consider a water solution in every stage of the water cycle: rainwater, runoff, potable, groundwater, greywater, and blackwater [7]. WSD has already several detailed strategies [1,18,21,22], and a comprehensive list of guidelines for several WSD strategies are found in Sharma et al. [15].

The aim of this study is not to detail every WSD strategy, but to demonstrate its intrinsic familiarity to architectural and urban design. However, despite all the available literature about WSD, it is still a topic in a dynamic process of definitions, demanding more research and data to verify that its strategies are effective and resilient. Moreover, the discussion about WSD in architecture and urbanism fields is limited. Therefore, the nature of WSD projects can still be experimental [23], which requires more time and practices. The large set of WSD strategies discussed in this section is already being applied by professionals to design cities and buildings, thus it should be integrated to undergraduate level education to reinforce connections to practice.

\subsection{Education}

The impact of promoting sustainability can be observed in the world's social and political agendas since the beginning of the 1990s [24] (see also ECO-92 outcomes), but the agendas for sustainability evolved in the 1970s environmental movements [25]. More important is that sustainability is a broad discipline in a process of transformation, its 
applicability in architecture and urban design needs more research and development of a consistent discourse due to its several challenges and demands. Overall, the efforts to introduce sustainable approaches in architectural education are observable since the early 1990s [26]. In Asia, for instance, sustainable modules range from 5\% to $25 \%$ in architectural education [27], denoting the different stages or interests in which it is incorporated to architecture courses.

As observed, most of WSD strategies are intimately connected to architectural and urban design. Some solutions are already part of the architectural glossary of sustainable solutions for quite a long time, for instance, green roofs, cisterns, or more recent, pervious pavements. On the one hand, these technologies might be employed individually without a consistent tool to align them together, reducing the possible impact it could generate as a system. The consequence is that the environmental and economic benefits might not be recognizable. On the other hand, an overview of such technologies must still be integrated in architects' education; as architect João Filgueiras Lima (Lelé) states "an architect is a generalist, not a specialist" [28], authors' translation]. Learning a wide range of approaches is part of the architectural profession, as design solutions respond to site and context.

The introduction of WSD in the design studio presents an opportunity to be expanded in the future academic career of students as supported by Altomonte [4]. He believes undergraduate students can be sensitized to a topic, to later validate at the master level, and criticize at the post-graduate level [4]. As shown earlier in Figure 1, WSUD and WSD are the most comprehensive terms that cover various aspects, including specific technologies, concepts, and broad principles. In this regard, they are the most relevant water-sensitive approaches that could be utilized as planning and design strategies, enabling students to integrate the ideas in their design process. Regarding the introduction of WSD in architectural education, as the above literature review suggests, the integration of WSD in the studio and its pedagogical descriptions are scarce. So far, there are three papers and only one syllabus describing some notions of WSD in architecture design studios. First, Tiwari et al. explained the development of an architectural design studio in which rainwater harvesting is selected as the topic [29]. Among the conclusions, they suggested that enough time should be given to the students to interact and discuss ideas related to water and technology. This experience is however not completely documented to provide enough evidence of WSD in a design studio.

The second case is reported by Rembeza and Kamrowska-Zaluska who briefly described WSD as one of the topics addressed by a group of architecture engineering students studying urban design [30]. The integration of WSD comes from students' own interests, but it is not clear how this topic emerged in the studio. As a positive aspect, Rembeza and Kamrowska-Zaluska emphasized the experience of joint international urban design studios to facilitate peer-to-peer learning [30]. This studio was proposed for postgraduate level where students could select topics more independently.

Finally, Blagojevic provided a complete description of urban design studios integrating water as a major topic [14]. Blagojevic also compared two sustainable urban design syllabi offered by Yale University School of Architecture [14]. The interdisciplinary method relies on the intersection of urban design with urban sociology, urban ecology and ecological urbanism, and landscape design by resorting to specific tasks while dealing with the site. The author verified that the introduction of water as a topic provides student focus and allows creativity to emerge on the design, "elaborating interrelationships between architectural and urban design, landscape design and water management techniques" [14]. The paper does not present evidence of designs.

More recently, Von Richthofen proposed the development of an architectural studio, to be called 'With/Out Water' [31] to consider the water-food nexus in Khulna, Bangladesh (this document consists of a syllabus plus documentation of students' projects), to discuss the connections between water, food production/consumption, and urbanization. The chosen site is composed by a system of ponds and canals with communities at risk, different from that of the previous papers, it is not a post-industrial site. The studio has a strong 
focus on the water topic and parametric design, but the notion of WSD is not mentioned. The quality of this studio is assured by a series of input lectures on diverse topics such as urban-rural ecosystems, humanitarian architecture, and ecosystems services, among others.

The cases presented above are integrating water in a studio with a range of comprehensiveness. An observed common aspect is that the introduction of WSD or water science in the design process gives a secure starting point for the project. Students feel more encouraged to start a design in which they can refer spaces and concepts to an open strategy from WSD. The cases emphasize the horizontal collaboration between students, the importance of community-oriented approaches, and interdisciplinarity.

\section{The Design Studio 'Blue Architecture'}

\subsection{Studio Specifications}

This study proposes the adoption of WSD as a main topic in an architectural design studio. It is titled Blue Architecture to convey the idea of water as design element. The studio follows the general indications of Wright on the criteria to integrate sustainability into architecture curriculum [32]. In our case, WSD is a theoretical framework, which means, the students define their own personal design approaches and assimilate WSD strategies along with the development of their projects. The studio aims at rethinking methods on how to design and implement solutions to improve the water cycle in cities. It shall be noted that due to the pedagogical nature of the architecture studio, the teaching methods aim to cultivate the students' awareness of WSD and its potential of being integrated into their design, rather than achieving a complete engineering solution of WSD. This will only be feasible in their future practice with multidisciplinary inputs and collaboration with other professionals.

An extract from the project brief explains the unit vision: "This unit invites students to explore a process of designing architecture and cities on waterfronts, in water or rethinking water flows in buildings and urban spaces". And contextualizes the expected results: "Projects must propose innovative and sustainable solutions to reduce consumption, to recycle and reuse, to promote access, and to preserve and clean water through design" (The authors, unpublished material). As extra supportive material, the broad goals of UN's SDG6 must be considered in the design process as indicative elements to achieve responsive solutions.

Blue Architecture is a year-long vertical design studio for architecture undergraduate students from year 3 and 4 . This studio proposes three phased design projects. In the first semester, two projects are completed (Table 2). The year 4 students lead mixed groups in the creation of a masterplan, which is the focus of this study due to its significant collaborative approach. The year 3 students support the masterplan in five weeks, and then move on to design a housing project within the masterplan.

Table 2. Studio structure. Source: authors.

\begin{tabular}{lcccc}
\hline & & \multicolumn{2}{c}{ First Semester } & Second Semester \\
\cline { 4 - 5 } & & Project 1 & Project 2 & Project 3 \\
\hline \multirow{2}{*}{ Student Year } & Third & \multirow{2}{*}{ Masterplan $^{1}$} & Housing & Cultural Program \\
\cline { 2 - 5 } & Fourth & & Project Brief & Public Program (Thesis) \\
\hline
\end{tabular}

${ }^{1}$ Focus of this study.

Blue Architecture proposes classic studio methods, such as: desk critics (two times per week); lectures by teaching team or guests; workshops; field trip and site visit; internal and external reviews (three times during the semester); plus, suggests contemporary approaches: short videos and documentaries; small conferences. These activities are part of the curriculum, aiming at developing students' skills and were planned before the semester started. However, some activities are introduced by reacting to students' progress or challenges, for instance, model materiality and oral presentation skills. Although Wright 
recommends some criteria to achieve sustainability in architecture curriculum [32], we have transformed these criteria to an architecture course. Approaches taken by teaching team or students are presented in Table 3.

Table 3. Criteria from Wright [32] vs. approaches for Blue Architecture studio.

\begin{tabular}{ll}
\hline \multicolumn{1}{c}{ Succinct Criteria [32] } & \multicolumn{1}{c}{ Blue Architecture Studio Approaches } \\
\hline 1. Social Engagement & Site visit, Community Interviews, Site analysis. \\
\hline 2. Learn different cultures & $\begin{array}{l}\text { Rich environment: professors, reviewers, and students from distinctive nationalities and } \\
\text { backgrounds. }\end{array}$ \\
\hline 3. Collectivity and Interaction & $\begin{array}{l}\text { Students from year 3 and 4 work together in mixed teams. } \\
\text { Students develop projects for Tectonics, Humanities, and Integrated Design to } \\
\text { Architecture in support to the studio design. }\end{array}$ \\
\hline 4. Environmental And Cultural context & $\begin{array}{l}\text { A post-industrial site is proposed for the design, which requires environmental } \\
\text { measures and offers substantial cultural background. Site is riverfront. }\end{array}$ \\
\hline 5. Technology and Environment & $\begin{array}{l}\text { Application of water strategies is the focus of the studio; however, other environmental } \\
\text { considerations are proposed by students. }\end{array}$ \\
\hline 6. Materiality & $\begin{array}{l}\text { Reuse, recycle, renovate, and retrofit are encouraged. } \\
\text { 7. Sustainability focus }\end{array}$ \\
$\begin{array}{l}\text { Readings in WSD are available in digital format (Moodle, online education platform of } \\
\text { the university) and physical (library). A WSD manual [1] is available in the studio, the } \\
\text { book River, Design, Space [33] is available for consultation in the library. }\end{array}$ \\
\hline
\end{tabular}

Students worked on tasks common to architectural and urban design: precedents studies; literature review; mapping; interview; photography; videos; architectural drawings; models; sketchbook. These tasks are documented and criticized every week by three tutors in groups or individually. Students' aim is to prepare a complete design documentation to be delivered at the end of the semester as the portfolio. Furthermore, this studio encouraged the students to identify their own interests and relevant theories to support their design concept and development, and to consider WSD as a guideline for any site intervention. This corresponds to the problem-based learning (PBL) concept in which students work on sustainable solutions for complex and real problems. PBL requires high levels of collaboration, integration of different disciplines, and development of citizenship mind. PBL formulates non-structured problems aiming at students' specific knowledge development and problem-solving skills [34].

A challenge in this studio is the interdisciplinarity; it was not possible to provide a point of view from analogue disciplines during the studio. However, the teaching team emphasized humanities, sustainable and technological aspects throughout the tutorials. The students redistribute amongst themselves tasks corresponding to different disciplines, for instance, historical research, environmental analysis, technological methods, and sociological issues. Moreover, the architecture program offers a complementary structure of modules, such as tectonics, humanities, environmental analysis, and integrated design to architecture. Finally, the external reviewers are from multidisciplinary backgrounds: landscape design, landscape architecture, architectural design, building design, and urban design, which is very helpful throughout the review sessions.

\subsection{Case Study}

Ningbo is a port city with 3.5 million inhabitants and strong presence of water; the rivers Yao and Fenghua connect in Ningbo, forming the river Yong that links to the Pacific Ocean. As a typical Jiangnan city, Ningbo has numerous meandering waterways (and streams). The water management of Ningbo can be traced back to the Tang-Song dynasties (ca. 960-1279). In the past, the city was known as the Asian Venice [35]. In average, it rains 13 days per month between 50 to $200 \mathrm{~mm}$ in Ningbo, precipitation is low in December and high in June (Table 4). The average rainfall in Ningbo is approximately $1400 \mathrm{~mm}$. However, the city is in a region with decreasing water availability in its watersheds [36]. In 2016, 
Ningbo became one of the first round of national-level pilot cities to apply the Chinese Sponge City Program (developed in 2013) [11], a guideline proposed to select Chinese cities to collect and utilize $80 \%$ of the stormwater in certain areas by 2030 [37].

Table 4. Average rainfall in Ningbo.

\begin{tabular}{ccccccccccccc}
\hline Rainfall & Jan & Feb & Mar & Apr & May & Jun & Jul & Aug & Sep & Oct & Nov & Dec \\
\hline $\mathrm{mm}^{1}$ & 73.2 & 77.6 & 133.9 & 105.6 & 114.6 & 198.1 & 178.3 & 166.7 & 170.8 & 83.1 & 75.0 & 54.7 \\
\hline days $^{2}$ & 12.6 & 12.3 & 16.9 & 15.3 & 14.7 & 16.4 & 13.1 & 14.5 & 14.1 & 10.3 & 8.9 & 8.5 \\
\hline
\end{tabular}

Data: ${ }^{1}$. China Meteorological Administration [38], ${ }^{2}$. Weather China Web Archive [39].

The site area is $0.28 \mathrm{~km}^{2}$ (approximately $700 \mathrm{~m} \times 400 \mathrm{~m}$ ) and is located in the district of Jiangbei, northeast of Ningbo, east of Rihu Park, and on the margin of the river Yong (Figure 3). The site is composed by a large industrial complex reminiscent of fishing companies. The site context encourages students to deal with historical, social, economic, and environmental aspects. Considering the natural topography, the site offers two challenges: the harbor waterfront and the risk of flooding caused by typhoons. Moreover, the site is identified and acquired by the municipality as part of a major transformation plan for the north riverbank of Yong River. Although the aim is to build a creative industrial zone, the municipal government has approved a masterplan that is predominantly commercial-oriented. The project brief and proposed designs thus explore the alternatives for recognizing the rich industrial heritage while exploring WSD as an alternative sustainable solution.
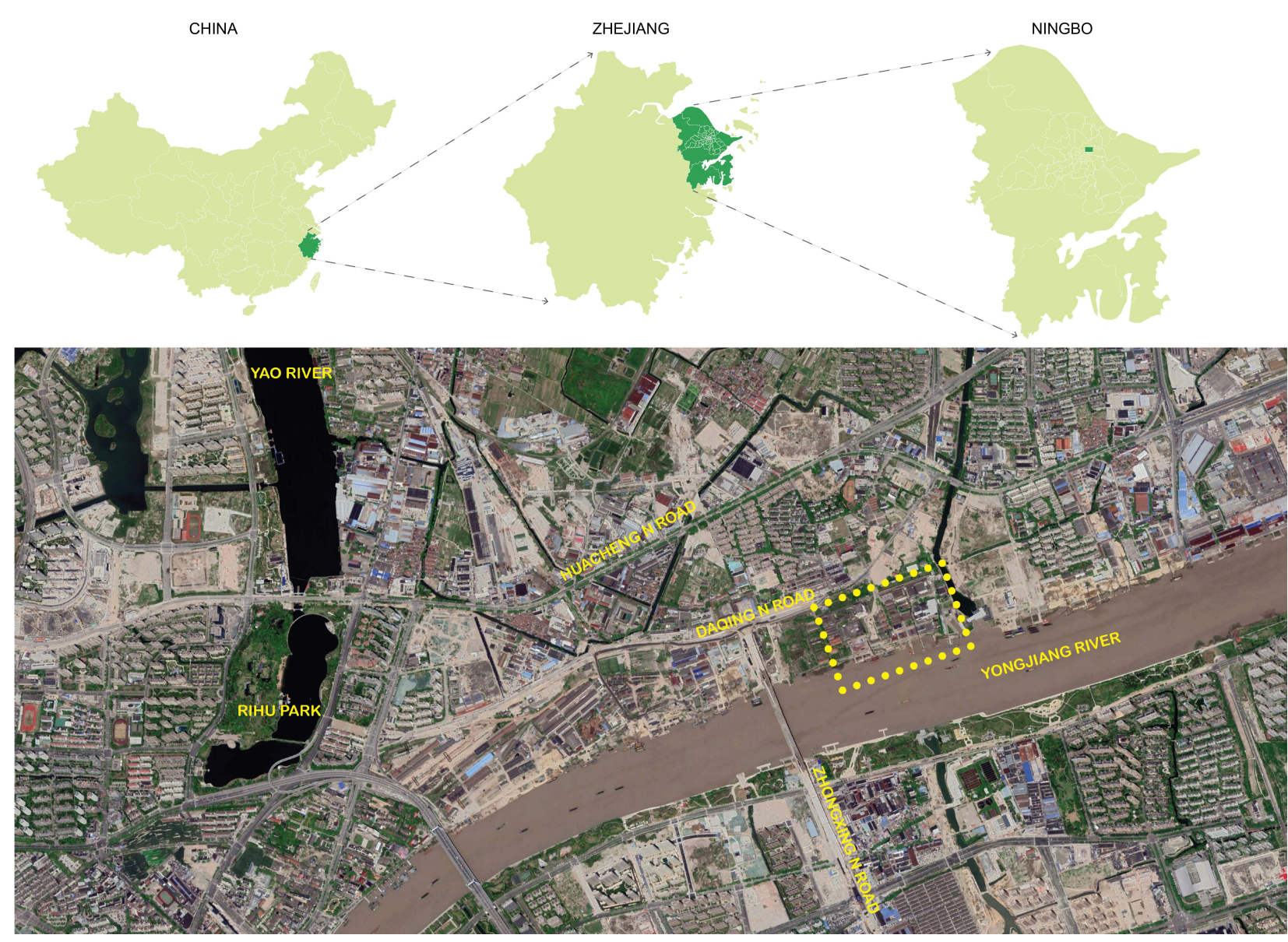

Figure 3. Selected site China, Zhejiang, Ningbo, Yong River waterfront. Satellite Image: Maxar Technologies, 2019, Google Earth. 


\subsection{Blue Architecture Masterplan Proposals}

Three groups are formed, and each is composed of eight students: four students from year 3 and four students from year 4; except for group 2 which has five students from year 4 . The vertical studio systems allow them to learn from each other and distribute tasks, but the masterplan design is led by year 4 students. The three groups have proposed masterplans to regenerate the site and balance the water cycle. The following explanations mainly focus on WSD reflected in the masterplans.

Students should analyze and understand the site from its ecological, socio-cultural, and economic perspectives in order to propose sustainable masterplans conciliating design and water at all moments. The projects should include solutions for housing which are developed in detail by students from year 3. Each group developed its own principles and concepts to integrate water in the design. The following paragraphs explain the masterplans of three groups, highlighting the main WSD strategies on each project.

Group 1 enquires about the Danwei system (the urban compound system created in the socialist period in China) found in the site, and proposed a design of an urban campus with open, free, and informal spaces. The project seeks to help individuals find their lost identities and create social bonding through offering various learning opportunities. One of the major features of this design is a water treatment canal running throughout the entire site (Figures 4 and 5). The canal adopts a set of solutions to clean the water collected from the river: floating residues filtration, biotopes (fish and different species of plants oxygenate the water), detention ponds, and wet/dry islands, in doing so it creates various public spaces catering for water-related activities that connect and integrate the project. The idea is to help to return clean water to the river and to utilize the system to integrate other strategies to absorb stormwater. Complementarily green spaces compose the masterplan. Figure 5 presents the layout of the proposed water filtration canals; Figure 6 presents six of the twenty urban spaces that compose the water filtration canals and their surrounding landscapes, these interventions aim to increase the water filtration and people's leisure. A list of solutions applied by group 1 is presented in Table 5 with its correspondent demands and outcomes.

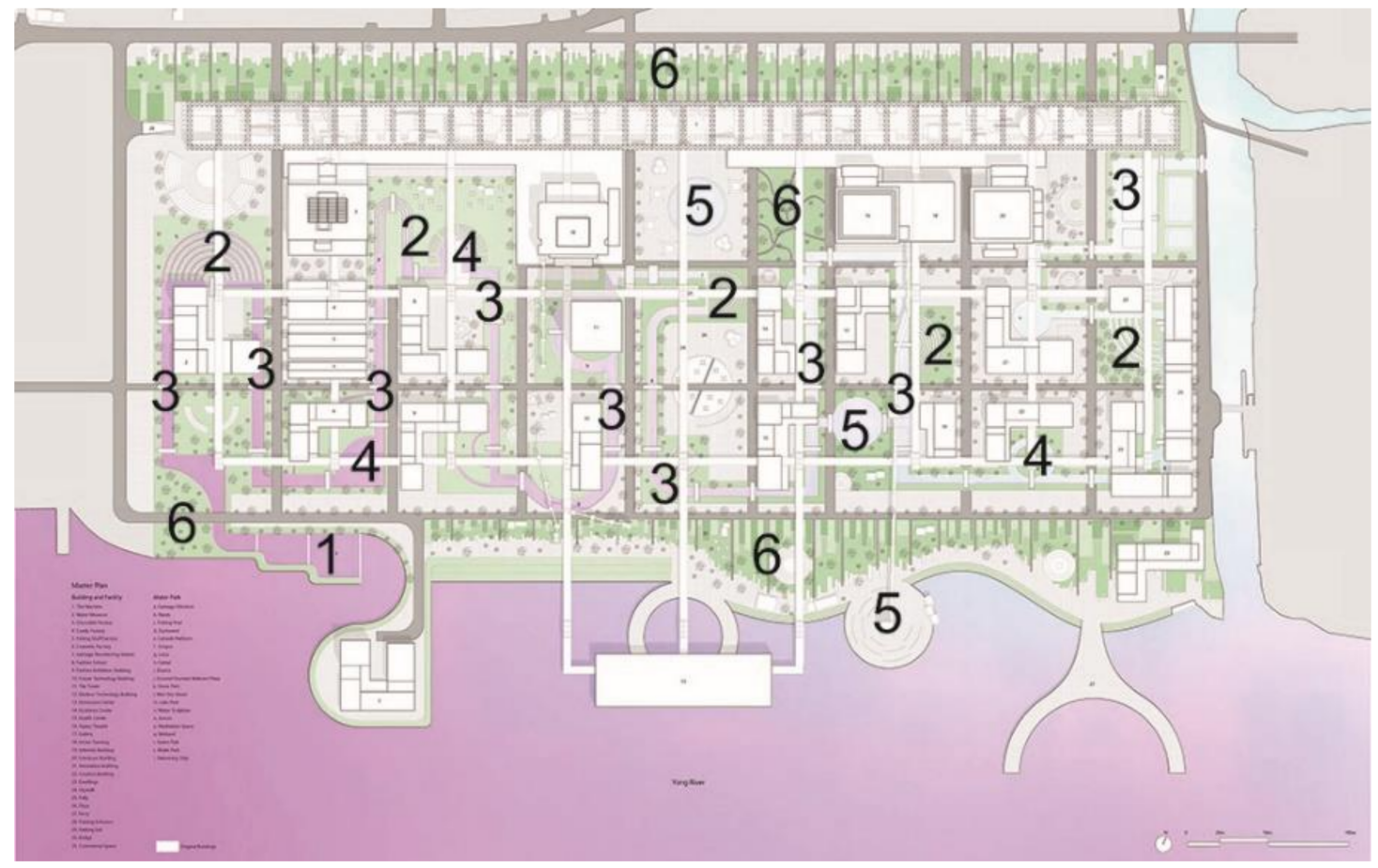

Figure 4. Masterplan Lifelong learning: 1. Floating residues filtration, 2. Biotopes, 3. Canals, 4. Detention Ponds, 5. Wet/dry islands, 6. Infiltration Zones (bio-swales), designed by: Tianning Ren, Yulin Zhang, Yixuan Chen, Jiamei Song, 2020. 


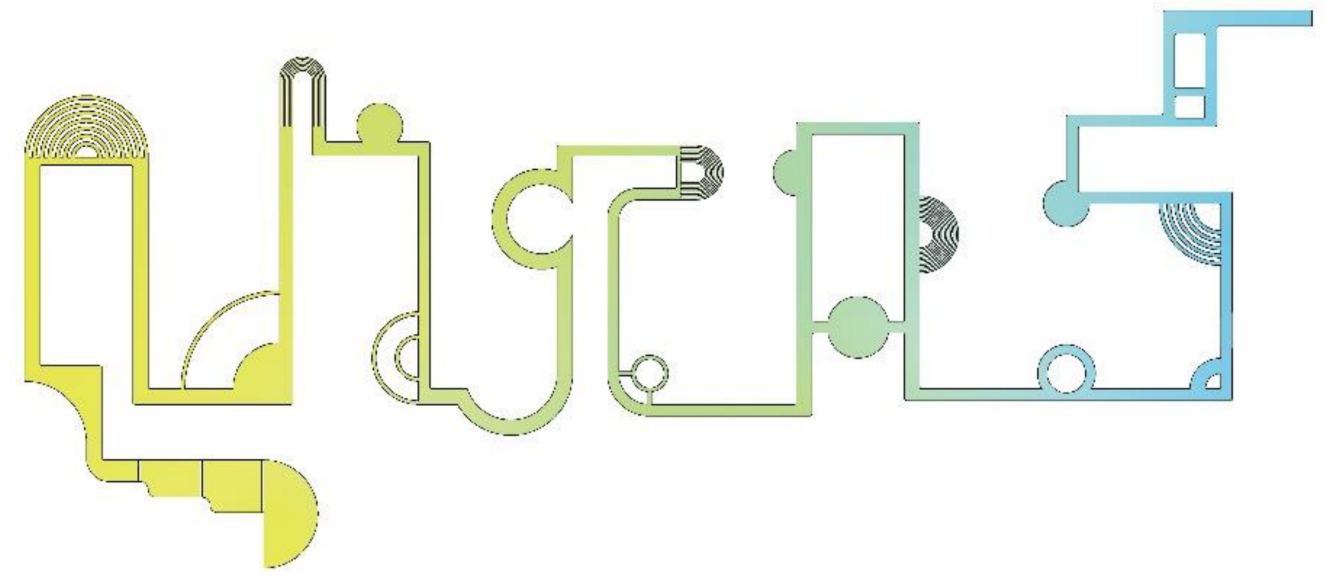

Figure 5. Proposed water cleaning canal, designed by: Tianning Ren, Yulin Zhang, Yixuan Chen, Jiamei Song, 2020.
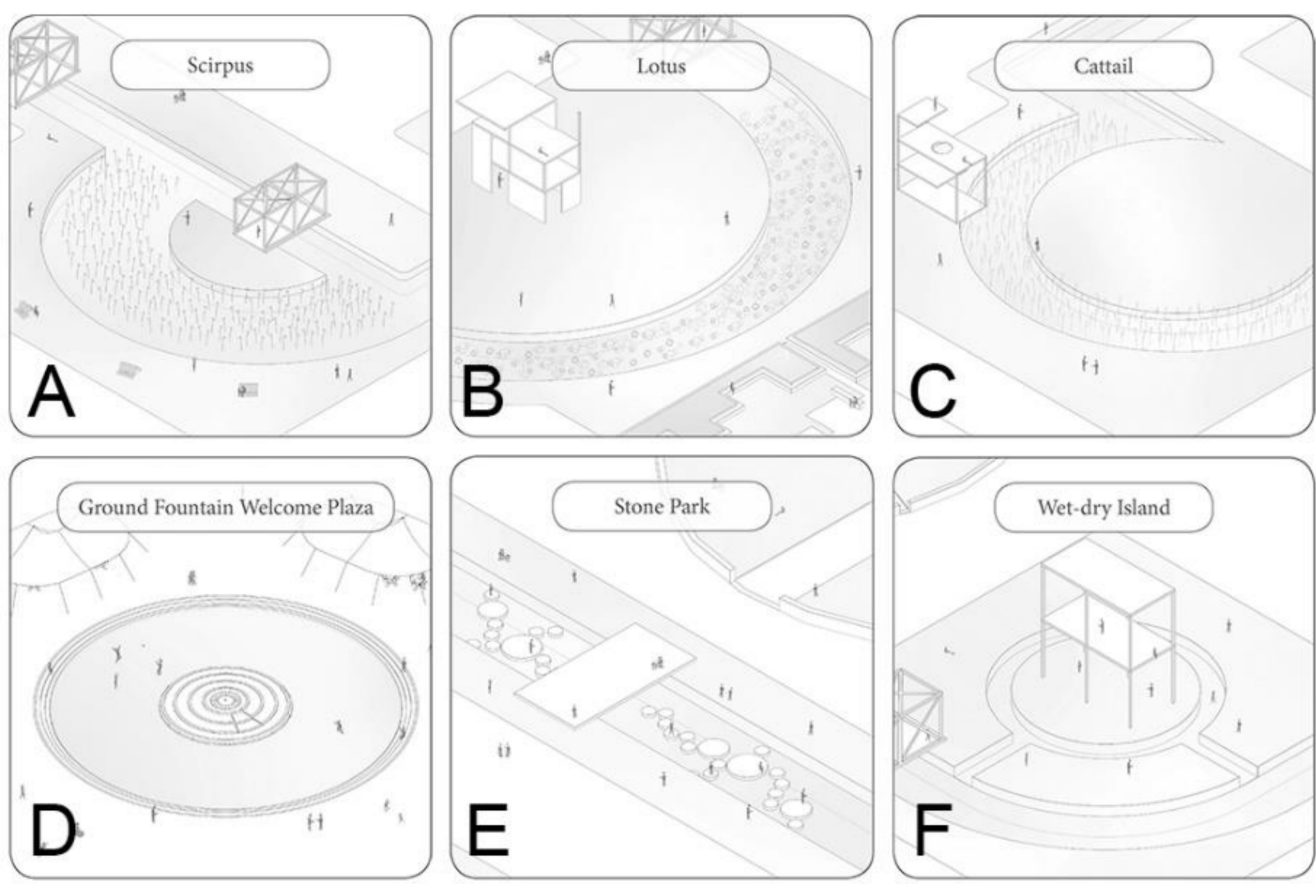

Figure 6. Six urban spaces connected to the water canal. Top row (A-C): diverse plant filtration; Bottom row (D-F): integration of public spaces to water features, designed by: Tianning Ren, Yulin Zhang, Yixuan Chen, Jiamei Song, 2020.

Group 2 conceptualizes the project into two narratives, physical and fictional. By observing society changes in Ningbo and investigating the site (where they have found female related ideas), they believe feminism as an urban design manifesto. The biggest industrial buildings are renovated to include a rainwater harvesting system made of tanks to redistribute the water. Close to the riverfront, they propose detention ponds; and in the center of the masterplan, a water treatment facility is placed to purify stormwater collected from a massive structure (Figure 7). Vertical changes in the landscape in the center of the masterplan host the water treatment facility, which is incorporated in a later phase of the design to respond to the space created. This facility acts as landscape creating a new topography which is layered with materials to filtrate stormwater. Figure 8 presents a detail of the proposed buildings for the masterplan; Figures 9 and 10 present how the topography perform in the design. Four major strategies are presented in Table 6. 
Table 5. Group 1 strategies. Source: Authors.

\begin{tabular}{ll}
\hline \multicolumn{1}{c}{ WSD Strategy * } & \multicolumn{1}{c}{ Students Approaches } \\
\hline $\begin{array}{l}\text { 1 Floating residues } \\
\text { filtration }\end{array}$ & $\begin{array}{l}\text { Demanded redesign of waterfront with a large canal, consideration of river } \\
\text { flow and tides, and consideration on social impacts. }\end{array}$ \\
\hline 2 Biotopes & $\begin{array}{l}\text { Demanded research on plants and animals with capacity for filtration, } \\
\text { consideration on program and landscape composition. }\end{array}$ \\
\hline Canals & $\begin{array}{l}\text { Demanded intensive design work to define shape, scale, interfaces; } \\
\text { resulted in opportunities for many design solutions and a wide range of } \\
\text { interaction with water. }\end{array}$ \\
\hline 4 Detention ponds & $\begin{array}{l}\text { Demanded research on materials and structure of detention pond, and } \\
\text { consideration on program. }\end{array}$ \\
\hline 5 Wet/dry islands & $\begin{array}{l}\text { A small solution for rain events to accumulate stormwater creating leisure } \\
\text { spaces and helping with evaporation; it has not been detailed due to time } \\
\text { constraints. }\end{array}$ \\
\hline F Infiltration zones & $\begin{array}{l}\text { It is included in the areas where the designers have planned parks and } \\
\text { recreational zones. }\end{array}$ \\
\hline * Same number sequence is followed in Tables 6-8.
\end{tabular}

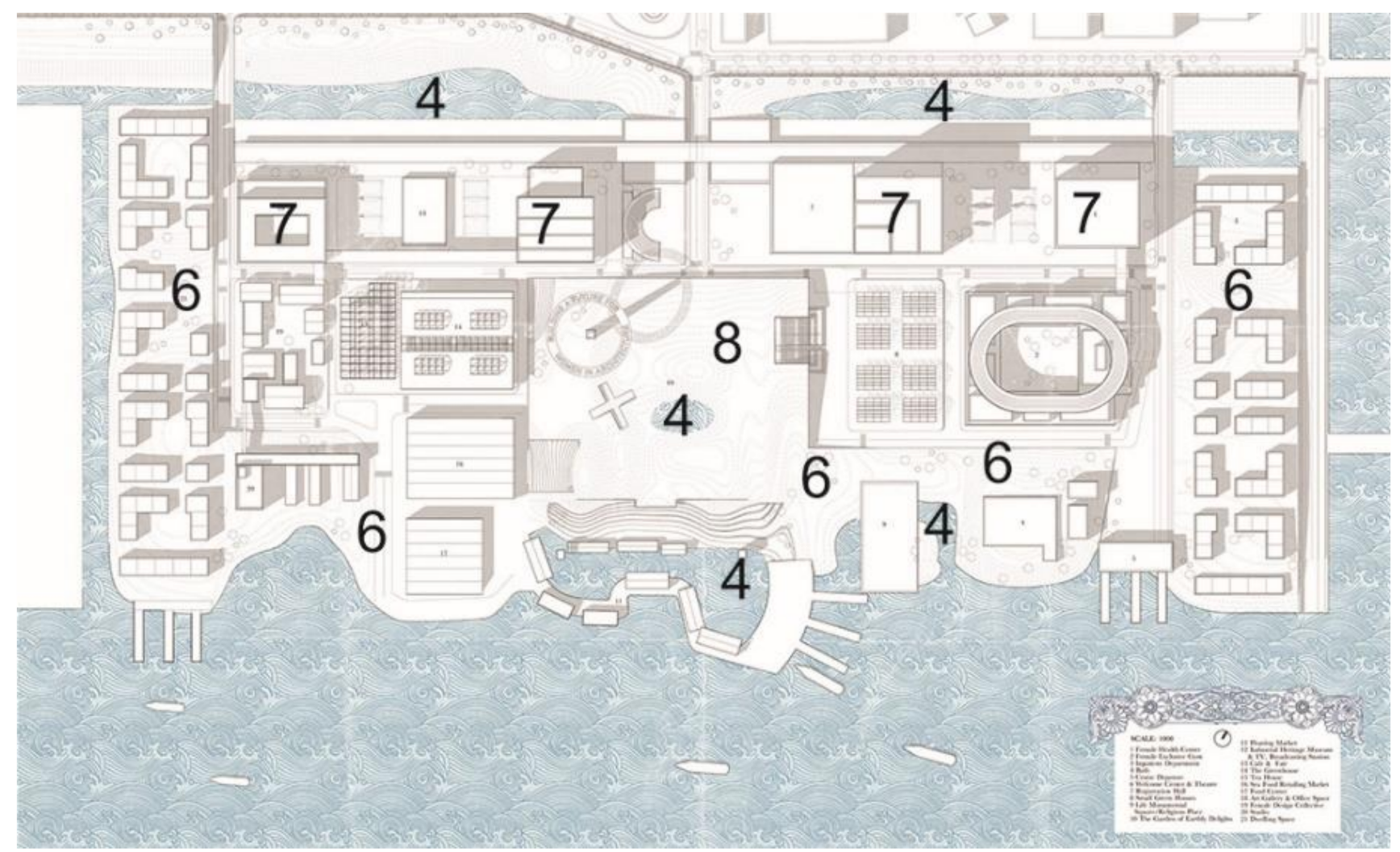

Figure 7. Masterplan metamorphosis, a selection of strategies' locations: 4. Detention ponds, 6. Infiltration Zones (bioswales), 7. Rainwater harvesting system, 8. Water treatment facility. Designed by: Siyuan Shen, Yanning Li, Felicia Gunawan, Eunsun Li, Yukuan Wang, 2020. 


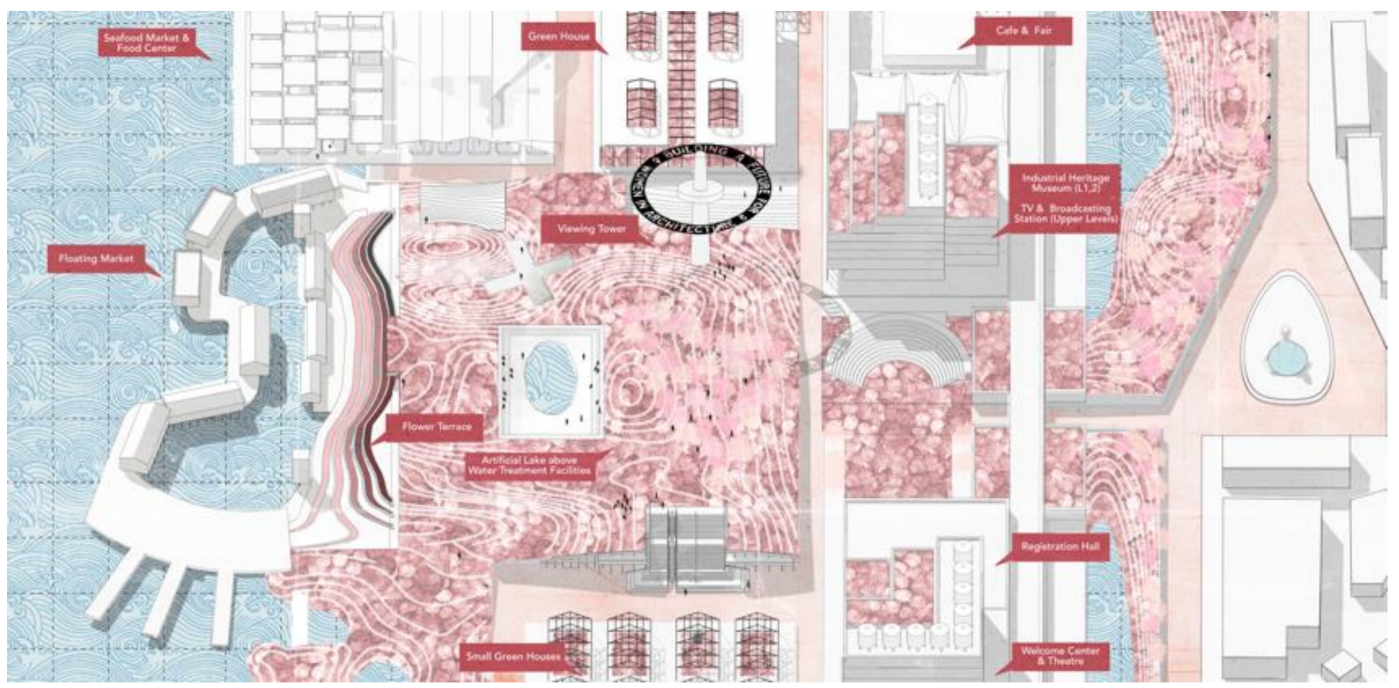

Figure 8. Masterplan detail presenting green public spaces and structures supporting WSD. Designed by: Siyuan Shen, Yanning Li, Felicia Gunawan, Eunsun Li, Yukuan Wang, 2020.

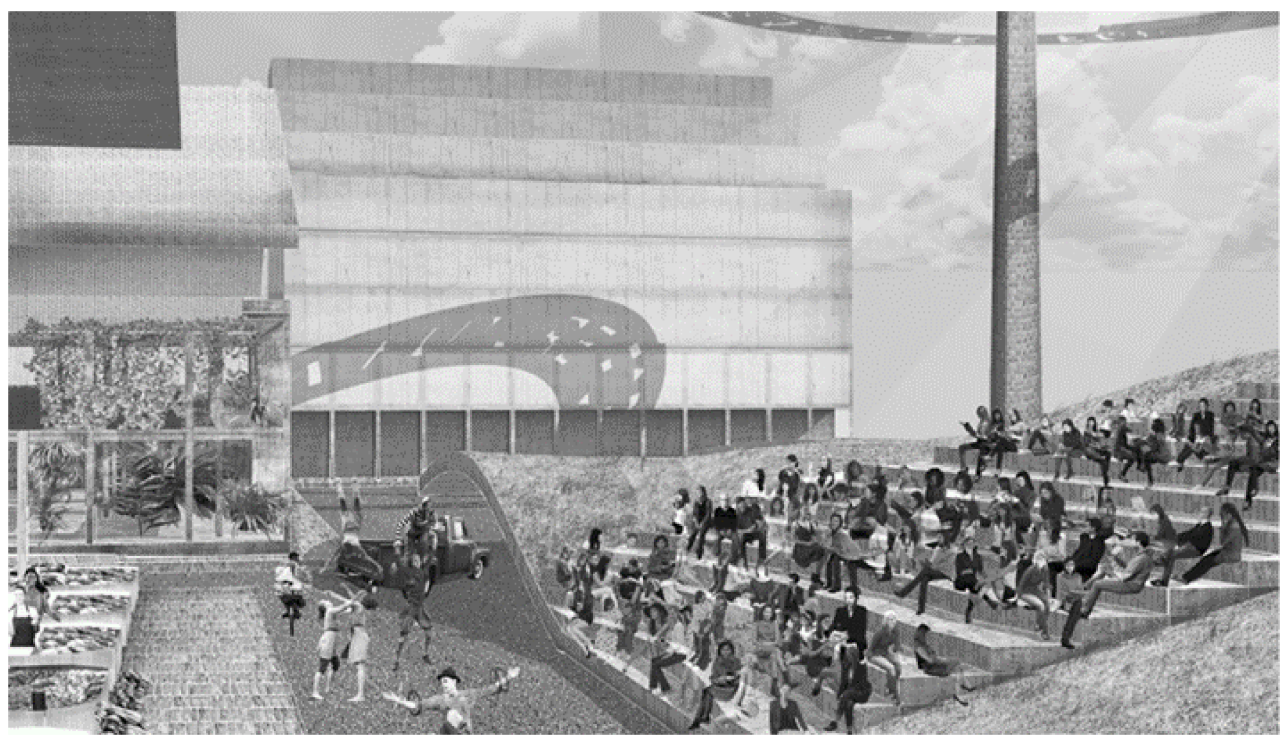

Figure 9. Render of open-air theater. Designed by: Siyuan Shen, Yanning Li, Felicia Gunawan, Eunsun Li, Yukuan Wang, 2020.

Table 6. Group 2 strategies. Source: Authors.

\begin{tabular}{ll}
\hline \multicolumn{1}{c}{ WSD Strategy * } & \multicolumn{1}{c}{ Students Approaches } \\
\hline 4 Detention ponds & $\begin{array}{l}\text { Demanded the redesign of waterfront, and consideration on social } \\
\text { aspects; these ponds are the result of vertical changes of the landscape. }\end{array}$ \\
\hline $\begin{array}{l}\text { 6 Infiltration zones } \\
\text { (bio-swale) }\end{array}$ & $\begin{array}{l}\text { Demanded an understanding of issues when creating new landscapes; } \\
\text { most of the urban plan has a topography that performs as the infiltration } \\
\text { zone. }\end{array}$ \\
\hline $\begin{array}{l}7 \text { Rainwater } \\
\text { harvesting system }\end{array}$ & $\begin{array}{l}\text { Demanded building redesign to incorporate tanks, and technical } \\
\text { research. }\end{array}$ \\
\hline $\begin{array}{l}\text { 8 Water treatment } \\
\text { facility }\end{array}$ & $\begin{array}{l}\text { Demanded an extensive understanding of surfaces, scale, ground, } \\
\text { borders, continuity; as result a massive filtration system is proposed. }\end{array}$ \\
*Same number sequence is followed in Tables 5,7 and 8.
\end{tabular}




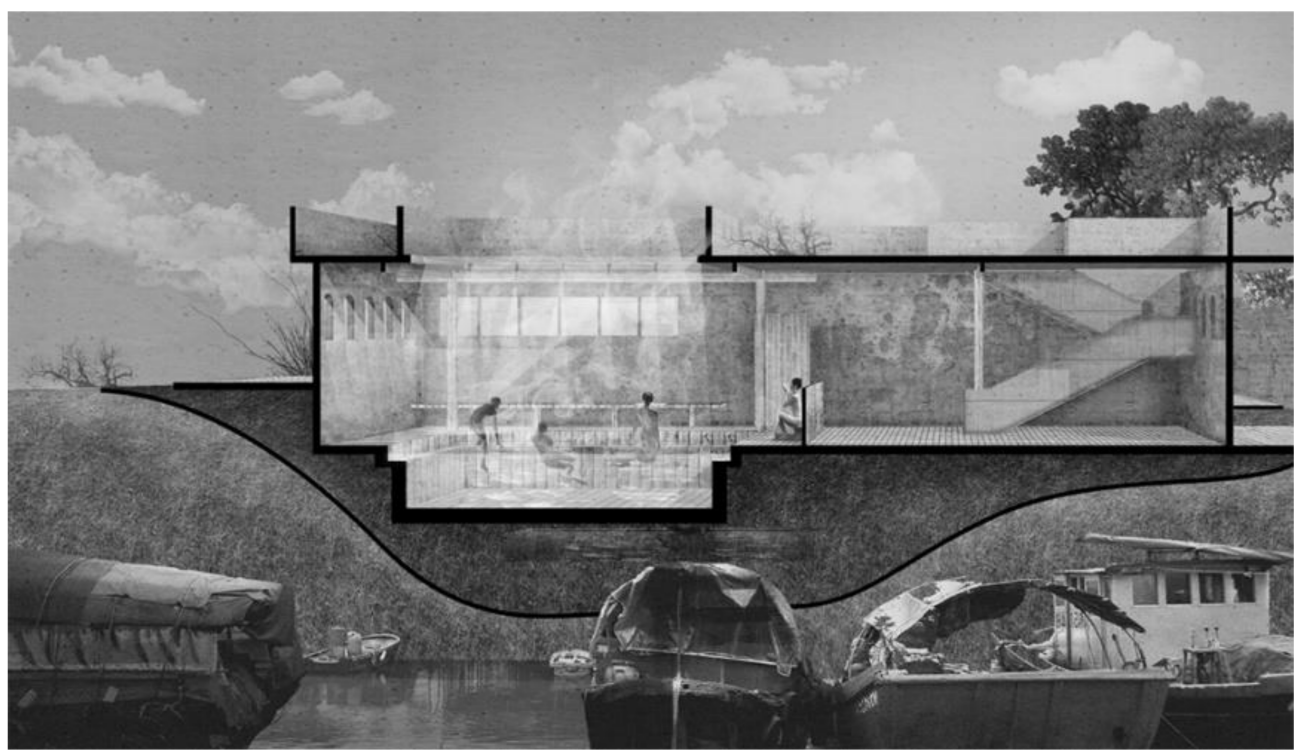

Figure 10. Section of bath. Designed by: Siyuan Shen, Yanning Li, Felicia Gunawan, Eunsun Li, Yukuan Wang, 2020.

Group 3 proposal is more rational than the other two, with a theme of contrasting visitors and locals, culture and work. The masterplan is divided and subdivided to create various public spaces in different scales. The contrasts between up and down, old and new, front and back, water and 'no-water' are regulated by a series of design-based rules. The group compares their interventions to traditional Chinese cities where the interactions with water ranged from intimate to intense, aiming at symbolic meanings of water in urban spaces. There is a big green patch performing as stormwater harvesting, and a system of ponds and narrow canals forming a water-based landscape complemented by green roofs (Figure 11).

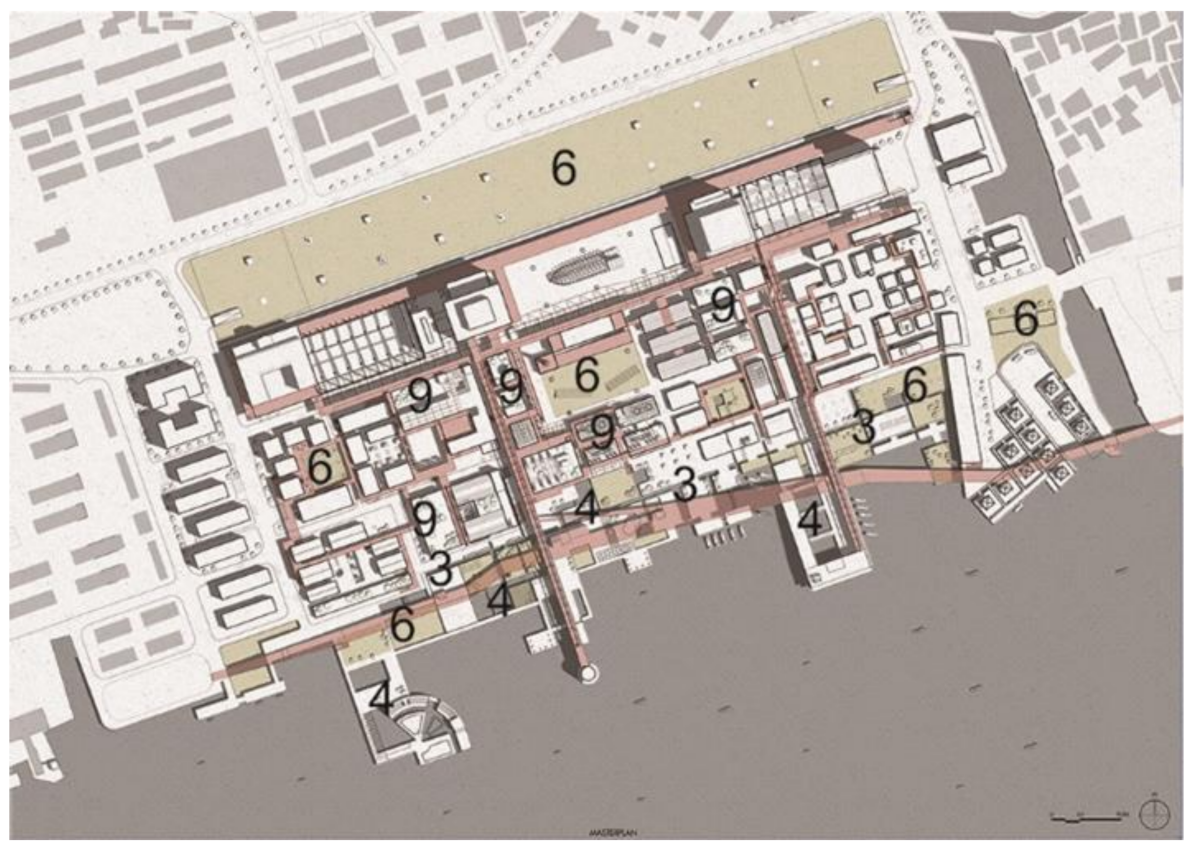

Figure 11. Masterplan coexistence agreement, a selection of strategies' locations: 3. Canals, 4. Detention ponds, 6. Infiltration zones, 9. Green roofs. Designed by: Zhengyou Chen, Tiancheng Kang, Yuhang Tao, Hanwen Xu, 2020. 
The group has generated solutions using the amount of water manifested in the urban space (Figure 12); close to the river they have created big water solutions, such as pools and entertainment engaging with water (10A), while in the opposite side, a park performs as bio-swale (10c). The summary of solutions from group 3 is presented in Table 7.
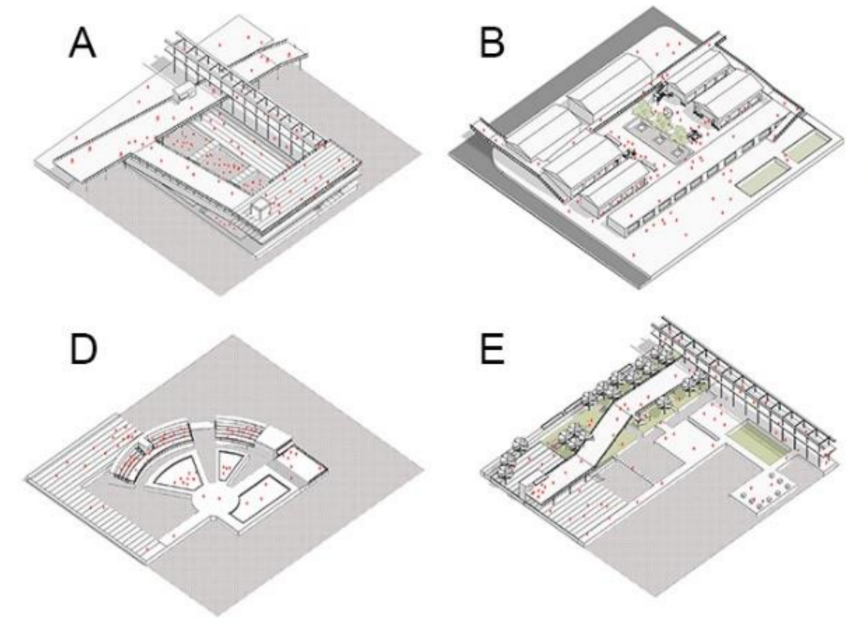
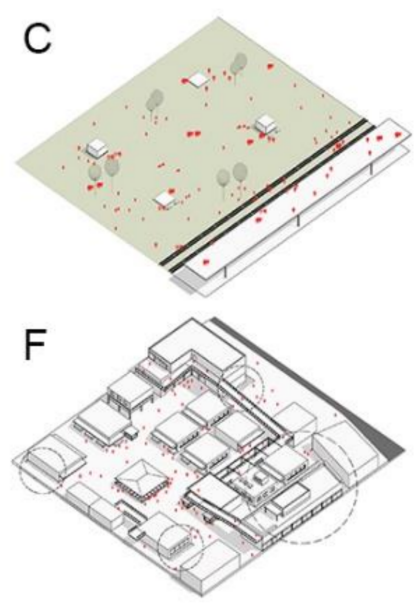

Figure 12. Top row (A-C): big water: swimming areas, medium water: studios, and small water: infiltration zone; Bottom row (D-F): big water: theater, medium water: view park, small water: market. Designed by: Zhengyou Chen, Tiancheng Kang, Yuhang Tao, Hanwen Xu, 2020.

Table 7. Group 3 strategies. Source: Authors.

\begin{tabular}{ll}
\hline \multicolumn{1}{c}{ WSD Strategy * } & \multicolumn{1}{c}{ Students Approaches } \\
\hline 3 Canals & $\begin{array}{l}\text { Demanded design work and landscape composition; the design is integrated into the buildings at a small } \\
\text { scale. }\end{array}$ \\
\hline 4 Detention ponds & $\begin{array}{l}\text { Demanded the redesign of waterfront and intensive design work on composition, shape, scale; a system } \\
\text { of ponds in different sizes and various levels of interaction between people and water. }\end{array}$ \\
\hline $\begin{array}{l}\text { 6 Infiltration zones } \\
\text { (bio-swale) }\end{array}$ & $\begin{array}{l}\text { Demanded an understanding of passive WSD strategies, and considerations on social aspects and } \\
\text { landscape; the green patch suggests the potential for other WSD strategies. }\end{array}$ \\
\hline 9 Green roofs & $\begin{array}{l}\text { Demanded research on technical aspects and plants; integration of the skywalks system and } \\
\text { entertainment spaces. }\end{array}$ \\
\hline
\end{tabular}

Presented in the masterplans above, WSD strategies are combined with the students' individual design preferences and theoretical approaches and manifested in the urban/architectural scales from large to small. The plans have created sustainable urban design solutions that will influence the building design in a later stage. In the urban design phase (semester 1), the students are getting familiar with the water topic, yet it is partially embraced in their solutions. Water as the design element was persistently encouraged by the tutors, changing the students' perception of sustainable urban design. This resulted in learning and investigating a new topic from the students themselves, but also in finding different ways of representing water dynamics in the design solutions.

\subsection{Blue Architecture Masterplan Indicators}

The three masterplans presented in this research have committed to integrating water in the design process since the early stages, which is the recommendation of WSD experts. The WSD strategies adopted by each group have reached different depth in terms of design process and final design; this is related to the students' comprehension of the selected strategy, and their capacities for interpreting and testing it into their designs. The impacts in the design process and the masterplan of adopting WSD strategies are presented in Table 8. This analysis does not measure the environmental or social impact of WSD strategies in a 
real application; it consists of a qualitative assessment describing what has been developed by these three groups throughout this experience.

Table 8. Qualitative assessment of impacts and potentialities of adopted WSD strategies observed in the development of Blue Architecture design studio regarding its capacity to generate sustainable spaces (based on the assessment of the designs and implications for a real project). Source: Authors.

\begin{tabular}{|c|c|c|c|c|}
\hline \multirow[b]{2}{*}{ WSD Strategy * } & \multirow{2}{*}{$\begin{array}{l}\text { Students' } \\
\text { Group }\end{array}$} & \multicolumn{2}{|c|}{ Impact in the: } & \multirow[b]{2}{*}{ Potential } \\
\hline & & $\begin{array}{l}\text { Design } \\
\text { Process }\end{array}$ & Project & \\
\hline $\begin{array}{l}1 \text { Floating } \\
\text { residues filtration }\end{array}$ & 1 & High & Medium & $\begin{array}{l}\text { This solution is limited to proximity to river or lake to allow } \\
\text { continuous flow of water. Just one group realized the need of such } \\
\text { strategy in the site context, which is applicable in such urban plan. }\end{array}$ \\
\hline 2 Biotopes & 1 & High & High & $\begin{array}{l}\text { This ecological strategy can create new landscapes for urban } \\
\text { spaces, however, the selection of plants must follow smart criteria } \\
\text { to reduce maintenance. This groups researched adequate plants to } \\
\text { perform different eco-functions. }\end{array}$ \\
\hline \multirow{2}{*}{3 Canals } & 1 & High & High & \multirow{2}{*}{$\begin{array}{l}\text { Artificial canals can be quite expensive to be implemented, } \\
\text { however, it can be a smart solution for dense urban contexts in } \\
\text { providing water collection spaces and artificial landscapes. }\end{array}$} \\
\hline & 3 & Medium & Low & \\
\hline \multirow{3}{*}{$\begin{array}{l}4 \text { Detention } \\
\text { ponds }\end{array}$} & 1 & Medium & Low & \multirow{3}{*}{$\begin{array}{l}\text { The detention ponds are used in all three masterplans. This } \\
\text { strategy provides flexibility of urban spaces being flooded mainly } \\
\text { in heavy rain events. This strategy has a big potential to generate } \\
\text { urban spaces and landscapes. }\end{array}$} \\
\hline & 2 & High & Medium & \\
\hline & 3 & High & High & \\
\hline 5 Wet/dry islands & 1 & Medium & Low & $\begin{array}{l}\text { Similar to detention ponds, the wet/dry islands will accumulate } \\
\text { stormwater, but evaporation is the active principle instead of } \\
\text { infiltration. This is one of the strategies that can enhance public } \\
\text { spaces in cities. }\end{array}$ \\
\hline \multirow{3}{*}{$\begin{array}{l}6 \text { Infiltration } \\
\text { zones } \\
\text { (bio-swales) }\end{array}$} & 1 & Low & Low & \multirow{3}{*}{$\begin{array}{l}\text { Infiltration zones are also used in all three masterplans. These } \\
\text { green patches are helpful to reduce stormwater surface runoff, } \\
\text { essential in a flat site. }\end{array}$} \\
\hline & 2 & Low & Medium & \\
\hline & 3 & Low & Low & \\
\hline $\begin{array}{l}7 \text { Rainwater } \\
\text { harvesting system }\end{array}$ & 2 & Medium & Low & $\begin{array}{l}\text { This solution can be implemented in small or big buildings and it } \\
\text { can be connected to roof surfaces. }\end{array}$ \\
\hline $\begin{array}{l}8 \text { Water treatment } \\
\text { facility }\end{array}$ & 2 & Low & High & $\begin{array}{l}\text { As strategy, it depends on government planning and } \\
\text { infrastructure. }\end{array}$ \\
\hline 9 Green roofs & 3 & Medium & High & $\begin{array}{l}\text { Architects are quite familiar with this strategy, and the } \\
\text { technologies have advanced to secure the building watertightness. }\end{array}$ \\
\hline
\end{tabular}

* Same number sequence is followed in Tables 5-7.

The impact in the design process is estimated by observing the students' problemsolving skills in the tutorials, including the clarity of the problem that they have articulated, the properness of the design solutions that they have proposed. The impact in the project is estimated by reviewing the documentation provided by each group and the feedback from external reviewers during the interim and final presentations. Although these criteria are subjective, they help to contextualize WSD strategies in a masterplan scale in an architecture design studio, it also supports students to understand how these solutions will be integrated into the building design in the future.

The WSD strategies selected by the groups offer many opportunities to generate innovative urban spaces. Group 1 is attentive to create a solution that considers more aspects of WSD and has an impact on the overall form of the urban space. Group 2 has faced some challenges to implement detailed WSD strategies as they had to re-organize time management and design concept during the semester. Group 3 has used a sensible approach connecting the scales of the design to traditional Chinese views of water, both symbolic and physically. Some of these strategies have consumed a significant amount 
of time for research and mostly design. Professors and students must be attentive to time management in such design studio set up, as research about WSD in urban design consumes time. Being an intrinsically interdisciplinary method, WSD will require many discussions and group work [40]. By contrasting the proposed strategies, it is possible to identify that the tasks performed by the students require multiple knowledge informing the design.

\section{Discussion}

This study focuses on learning the available cases of WSD integrated in architectural and urban design and observing pedagogical aspects of a practical application of WSD in a design studio teaching. It considers water as one of the main challenges in the sustainability spectrum and its relevance to UN's SDG6. In the literature review section, only four cases concerning the water topic in a design studio environment have been identified; they provide design approaches towards water and cities. These case studies support the idea that WSD helps architectural students to design by creating collaborations, integrating technology, and associating with different disciplines, thereby increasing creativity in the design process. Certainly, the masterplan projects produced in Blue Architecture studio have achieved sustainable levels that are aligned with design practice, too. WSD consists of an innovative contemporary ecological method to design sustainable cities. On the other hand, more studies conducted in architecture design studios are needed to disseminate the knowledge about the topic. He et al. identified technical barriers for implementation of SCP such as education and training to promote sustainable cities [41]. Thus, cultivating the awareness of WSD for architectural students is a key point.

The Blue Architecture studio proposes to incorporate WSD as a main topic generating a background for theoretical approach in sustainability integrated to the design process. It is a strategy to 'sensitize' undergraduate students to sustainability, as suggested by Altomonte [4], in this case, in relation to water. The lack of familiarity with the topic might create challenges for the students to adopt WSD in the first stages of the design process. In the beginning, the students found it difficult to connect the technical solution to the creation of social spaces around water. Nevertheless, the continuous provision of educational material and the connections between the design task and WSD strategies helped them to overcome this problem. Therefore, interdisciplinarity is essential for such design studio, though it is not always possible in the architectural design education, these changes must be implemented, as pointed by Altomonte [4]. In this sense, the teaching team must equip the course with a wide variety of learning materials, digital and analogic, such as input lectures, videos, texts, and manuals, covering sociological, environmental, and technical aspects of WSD. The time demand for interdisciplinary integration must be reflected on the duration of the studio. The proposed studio has only five weeks duration, which might be too short for more thought-out designs.

The proposed architecture design studio innovates by providing a multidisciplinary ecological approach with great potential to leverage students' creativity on sustainability. The goal is not to form experts in WSD, but to contribute to their ability to discuss and propose sustainable solutions considering water. The architectural design studio can accommodate such topics without major changes in the whole curriculum of the course. One positive aspect is the flexible response to the local context in terms of the water cycle, which will generate specific design strategies/solutions at the end.

This study identifies the lack of scientific reports on WSD integrated to architectural design, however, this does not confirm that WSD is totally unconsidered in design studios. Not all pedagogical innovations are documented as a scientific paper. In fact, some cases integrate WSD with a variety of other sustainable topics in which students can select their approaches to design projects. This reflects that sustainable design studios are still evolving and are open to a wide range of methods and tools. Certainly, the architectural field will benefit from discussing and assimilating new sustainable innovations, in particular, interdisciplinary methods in architectural education. Interdisciplinarity has been on the 
top of contemporary discussion in academic research for several decades, and so it can contribute to learning. It is a research methodology where researchers get insights from analogue disciplines [40] to solve complex problems.

Again, the demand for high quality WSD pedagogical material (book, manual, and guideline) produced specifically for architects is one of the challenges faced in such studio's environments. Interdisciplinary tools, such as WSD, are more advanced in humanities and natural or social sciences [40]. Although architecture has a leg on each of these sciences, not many available materials are related to the topic. Alternatively, 'River, space, design' [33] is a suitable example of material designed for architects, because it presents information displayed as visual content, technical details, and successful real examples. Having WSD material can encourage architects and urban designers to lead the design in interdisciplinary teams, but other perspectives must be part of learning materials. This study has a unique contribution to architectural education by reviewing the available literature and providing an approach on how to integrate WSD in design studio, a topic that is scarce in current literature despite its high applicability in design practice and effectiveness on enhancing sustainability.

Opportunities for learning WSD range in various design scales. Learning several WSD strategies will benefit architectural students in different levels, for example, detailing of green roofs; water sources, flow and management; dry and wet public spaces; water as active landscape; and water reuse and recycling. Here, the notion of transitioning from supplying water and sewage to an adaptive social and environmental infrastructure, as pointed by Brown et al. [42], must be understood by architectural students. This studio was limited in its capacity of offering lectures from relevant disciplines, which was solved by suggesting supplementary learning material: videos and texts. Support material or interdisciplinary exchanges must be considered in each studio situation. Clearly, a WSD implementation would be more successful when considered since the beginning of the design, which has been reported by Hoyer et al. [1], and when is applied through collaborative planning [15].

Overall, the masterplan projects produced in this studio have reached a good level of details for WSD strategies in such a short timeframe, which also suggests that more time is needed for further development. Students in advanced courses (postgrad) or full interdisciplinary design studios can be capable of developing fully integrated WSD strategies in urban and architectural scale. These advanced students are more equipped to explore architectural details, estimating volumes of water, consumption, and implementation costs or defining more holistic plans. A collaborative design approach can be established by connecting architectural students to other disciplines. In sum, WSD as a pedagogical tool allows the teaching team to balance the level of detailing that must be achieved in such projects according to students' progress and experience.

\section{Conclusions}

Introducing WSD in an architectural design studio poses several challenges to educators: the idea of preserving and transforming natural and urban structures; the reasoning about integrated ecological approaches in urbanism respecting natural cycles is a complex task; and the lack of pedagogical material that can be easily assimilated by architects. For instance, Radcliffe concluded that the lack of familiarity with WSD slows down the process of adoption of such strategies in design [17]. Similarly, Lee and Yigitcanlar assigned barriers for WSD is the lack of understanding of its features and benefits, lack of technical skill sets, and limited research and knowledge [43]. Therefore, the understanding of WSD can be gradually build in students' curriculum from the undergraduate level. To extend the discussion on the proposed masterplans, we planned a public exhibition on the site to cultivate and disseminate the awareness of WSD to the general public.

This study relies on exploratory and descriptive research, analyzing the literature on the topic of WSD in architectural education and documenting an architectural design studio that proposes a water-oriented design approach. The results of this study suggest 
that WSD can be incorporated into a design studio topic due to its tangible tools and strategies towards water. The teaching team has control of the level of detailing in the project, from abstract concepts of WSD to technical integrated solutions. We conclude that the lack of pedagogical methods, teaching explorations, and instructional materials might be an impediment to the dissemination of WSD in architectural and urban design studios. Moreover, learning WSD can contribute to architects' leadership when it comes to propose Water Sensitive Design, Water Sensitive Urban Design, or Water Sensitive Cities in the future. Through presenting a particular architectural education case, in which the concept and strategies of WSD are well integrated, this study also contributes to the development of comprehensive approaches in architectural pedagogy.

Author Contributions: Conceptualization, M.S. and J.X.; methodology, M.S., J.X. and A.C.; investigation, M.S. and J.X.; writing—original draft preparation, M.S.; writing-review and editing, M.S., J.X. and A.C.; visualization, M.S. All authors have read and agreed to the published version of the manuscript.

Funding: This research received no external funding.

Institutional Review Board Statement: Not applicable.

Informed Consent Statement: Not applicable.

Data Availability Statement: All data produced or generated in this research appears in the submitted paper.

Conflicts of Interest: The authors declare no conflict of interest.

\begin{abstract}
Acronyms
CRC: Cooperative Research Centre (for Water Sensitive Cities); DPLG: Department of Planning and Local Government (Australia); GI: Green Infrastructure; LID: Low Impact Development; PBL: Problem-Based Learning; SCMs: Stormwater Control Measures; SCP: Sponge City Program; SDGs: Sustainable Development Goals; SQIDs: Stormwater Quality Improvement Devices; UN: United Nations; WSC: Water Sensitive Cities; WSD: Water Sensitive Design; WSUD: Water Sensitive Urban Design.
\end{abstract}

\title{
References
}

1. Hoyer, J.; Dickhaut, W.; Kronawitter, L.; Weber, B. Water Sensitive Urban Design: Principles and Inspiration for Sustainable Stormwater Management in the City of the Future; SWITCH-Managing Water for the City of the Future; HafenCity Universität Hamburg: Hamburg, Germany, 2011. Available online: http://www.switchurbanwater.eu/outputs/pdfs/w5-1_gen_man_d5.1.5_manual_ on_wsud.pdf (accessed on 10 September 2019).

2. Panayotopoulos-Tsiros, D. Eleonas: Urban voids as opportunity for a water sensitive approach to the design of cities. In Atiner's Conference Paper Series; PLA2015-1809; Athens Institute for Education and Research: Athens, Greece, 2016.

3. UN Water. The United Nations World Water Development Report 2018: Nature-Based Solutions for Water; World Water Assessment Programme; UNESCO; United Nations Educational, Scientific and Cultural Organization: Paris, France, 2018; Available online: www.unwater.org/publications/world-water-development-report-2018/2018 (accessed on 10 November 2020).

4. Altomonte, S. (Ed.) Education for Sustainable Environmental Design: The EDUCATE Project; EDUCATE Press, University of Nottingham: Nottingham, UK, 2012; Available online: https:/ / www.researchgate.net/publication/331528095_EDUCATION_ FOR_SUSTAINABLE_ENVIRONMENTAL_DESIGN_THE_EDUCATE_PROJECT (accessed on 20 August 2020).

5. UN. United Nations Sustainable Development Goals. Goal 6 Clean Water and Sanitation. Available online: https://www.un.org/ sustainabledevelopment/water-and-sanitation/ (accessed on 10 November 2020).

6. Fletcher, T.D.; Shuster, W.; Hunt, W.F.; Ashley, R.; Butler, D.; Arthur, S.; Trowsdale, S.; Barraud, S.; Semadeni-Davies, A.; BertrandKrajewski, J.C.; et al. SUDS, LID, BMPs, WSUD and more: The evolution and application of terminology surrounding urban drainage. Urban Water J. 2015, 12, 525-542. [CrossRef]

7. DPLG-Department of Planning and Local Government. Water Sensitive Urban Design Technical Manual for the Greater Adelaide Region; Government of South Australia: Adelaide, Australia, 2009. Available online: https://www.watersensitivesa.com/ resources/technical-aides/guidelines/technical-manual-for-water-sensitive-urban-design-in-greater-adelaide/ (accessed on 15 September 2019). 
8. Sharma, A.K.; Pezzaniti, D.; Myers, B.; Cook, S.; Tjandraatmadja, G.; Chacko, P.; Chavoshi, S.; Kemp, D.; Leonard, R.; Koth, B.; et al. Water sensitive urban design: An investigation of current systems, implementation drivers, community perceptions and potential to supplement urban water services. Water 2016, 8, 272. [CrossRef]

9. Dai, L.; van Rijswick, H.F.; Driessen, P.P.; Keessen, A.M. Governance of the Sponge City Programme in China with Wuhan as a case study. Int. J. Water Resour. Dev. 2018, 34, 578-596. [CrossRef]

10. Li, L.; Collins, A.M.; Cheshmehzangi, A.; Chan, F.K. Identifying enablers and barriers to the implementation of the Green Infrastructure for urban flood management: A comparative analysis of the UK and China. Urban For. Urban Green. 2020, 54, 126770. [CrossRef]

11. Sun, J.; Cheshmehzangi, A.; Wang, S. Green Infrastructure practice and a sustainability key performance indicators framework for neighbourhood-level construction of Sponge City Programme. J. Environ. Prot. 2020, 11, 82-109. Available online: https: $/ /$ m.scirp.org/papers/98124 (accessed on 15 September 2019). [CrossRef]

12. Jia, H.; Sun, Z.; Li, G. A four-stage constructed wetland system for treating polluted water from an urban river. Ecol. Eng. 2014, 71, 48-55. [CrossRef]

13. Leng, L.; Jia, H.; Chen, A.; Zhu, D.; Xu, T.; Yu, S. Multi-objective optimization for green-grey infrastructures in response to external uncertainties. Sci. Total Environ. 2021, 775. [CrossRef]

14. Blagojevic, L. Mediating Post-Industrial City Issues and Realities in the Study Process: Innovating Architecture Design Studio Curricula and Teaching Methodology. In Proceedings of the International Scientific Conference and XXIV Meeting of Serbian Surveyors, Professional Practice and Education in Geodesy and Related Fields, Kladovo, Serbia, 24-26 June 2011; Available online: https://www.academia.edu/7589518/Mediating_Post_Industrial_City_Issues_and_Realities_in_the_Study_Process_ Innovating_Architecture_Design_Studio_Curricula_and_Teaching_Methodology (accessed on 20 April 2020).

15. CRC for Water Sensitive Cities. Water Sensitive Cities. Cooperative Research Centre for Water Sensitive Cities. 2018. Available online: https://watersensitivecities.org.au/content_type/academic-publication/ (accessed on 10 February 2020).

16. Sharma, A.K.; Gardner, T.; Begbie, D. Approaches to Water Sensitive Urban Design: Potential, Design, Ecological Health, Urban Greening, Economics, Policies, and Community Perceptions; Elsevier: Amsterdam, The Netherlands, 2019. [CrossRef]

17. Radcliffe, J.C. History of Water Sensitive Urban Design/Low impact development adoption in Australia and Internationally. In Approaches to Water Sensitive Urban Design: Potential, Design, Ecological Health, Urban Greening, Economics, Policies, and Community Perceptions; Sharma, A.K., Gardner, T., Begbie, D., Eds.; Elsevier: Amsterdam, The Netherlands, 2019; pp. 1-24. [CrossRef]

18. Wong, T.H.F. An overview of water sensitive urban design practices in Australia. Water Pract. Technol. 2006, 1, 1. [CrossRef]

19. Visconti, C. Socio-technical aspects of Water Sensitive Urban Design: Micro-scale innovative tools for adaptation. J. Urban Plan. Landsc. Environ. Des. 2017, 2, 241-262. [CrossRef]

20. Sharma, A.K.; Rashetnia, S.; Gardner, T.; Begbie, D. WSUD design guidelines and data needs. In Approaches to Water Sensitive Urban Design: Potential, Design, Ecological Health, Urban Greening, Economics, Policies, and Community Perceptions; Sharma, A.K., Gardner, T., Begbie, D., Eds.; Elsevier: Amsterdam, The Netherlands, 2019; pp. 75-86. [CrossRef]

21. Hoban, A. Water Sensitive Urban Design approaches and their description. In Approaches to Water Sensitive Urban Design: Potential, Design, Ecological Health, Urban Greening, Economics, Policies, and Community Perceptions; Sharma, A.K., Gardner, T., Begbie, D., Eds.; Elsevier: Amsterdam, The Netherlands, 2019; pp. 25-47. [CrossRef]

22. Smith, M.; Hargroves, K.; Desha, C.; Stasinopoulos, P. Water Transformed-Australia: Sustainable Water Solutions for Climate Change Adaptation; The Natural Edge Project-TNEP; Griffith University: Brisbane, Australia; Australian National University: Canberra, Australia, 2009; Available online: https: / / eprints.qut.edu.au/85206/ (accessed on 5 April 2020).

23. Daglio, L. Building with water: Innovative approaches for sustainable architecture. In Proceedings of the International Conference in Architecture and Urban Design, 2nd ICAUD, Tirana, Albania, 8-10 May 2014; Available online: https:/ /www.academia.edu/ 17117968/Building_with_water_innovative_approaches_for_sustainable_architecture (accessed on 8 April 2020).

24. Ryu, H.C.; Brody, S.D. Examining the impacts of a graduate course on sustainable development using ecological footprint analysis. Int. J. Sustain. High. Educ. 2006, 7, 158-175. [CrossRef]

25. Walker, P. Sustainability: A discipline and a political agenda? Environ. Hazards 2017, 16, 93-98. [CrossRef]

26. McHarg, I.L. Design with Nature; Wiley: New York, NY, USA, 1992.

27. Álvarez, S.P.; Lee, K.; Park, J.; Rieh, S.Y. A comparative study on sustainability in architectural education in Asia-with a focus on professional degree curricula. Sustainability 2016, 8, 290. [CrossRef]

28. Leonidio, O. Eu vivo numa ilha: Entrevista com João Filgueiras Lima, Lelé. Entrevista 2014, São Paulo, Brazil, ano 15, n. 058.01, Vitruvius. Available online: https://vitruvius.com.br/index.php/revistas/read/entrevista/15.058/5170? page =2 (accessed on 9 May 2020).

29. Tiwari, M.; Bongirwar, R.; Sambare, P.; Sinhal, S. Environmental issue and its implication in architecture design pedagogy. Int. J. Res. Civ. Eng. Archit. Des. 2016, 4, 122-129. Available online: https://www.academia.edu/26929741/Environmental_Issue_and_ Its_Implication_in_Architecture_Design_Pedagogy (accessed on 9 April 2020).

30. Rembeza, M.; Kamrowska-Zaluska, D. The resilient city in architectural engineering education: A joint design studio between Gdańsk and Chalmers universities of technology. World Trans. Eng. Technol. Educ. 2019, 17. Available online: https:/ /www.researchgate.net/publication/340665596_The_resilient_city_in_architectural_engineering_education_a_joint_ design_studio_between_Gdansk_and_Chalmers_universities_of_technology (accessed on 8 April 2020). 
31. Von Richthofen, A. With/out Water: Architecture within a Water-Food Nexus in Khulna, Bangladesh; NUS School of Design and Environment, Department of Architecture: Singapore, 2019; Available online: https:/ / www.research-collection.ethz.ch/handle/ 20.500.11850/343461 (accessed on 10 April 2020).

32. Wright, J. Introducing sustainability into the architecture curriculum in the United States. Int. J. Sustain. High. Educ. 2003, 4, 100-105. [CrossRef]

33. Prominski, M.; Stokman, A.; Stimberg, D.; Voermanek, H.; Zeller, S.; Bajc, K. River, Space, Design: Planning Strategies, Methods and Projects for Urban Rivers; Birkhäuser: Basel, Switzerland, 2012.

34. Markham, T.; Larmer, J.; Ravitz, J. Aprendizagem Baseada em Projetos: Guia Para Professores do Ensino Fundamental e Médio, 2nd ed.; Artmed: Sao Paulo, Brazil, 2008.

35. Griffiths, J.; Chan, F.; Tang, Y.T. The development of water management within Ningbo, Zhejiang, China. In Proceedings of the International Association for Hydro-Environment Engineering and Research World Congress, IAHR World Congress, Chengdu, China, 8-13 September 2013. Available online: https:/ / www.researchgate.net/publication/282356844_The_Development_of_ Water_Management_within_Ningbo_Zhejiang_China (accessed on 5 June 2020).

36. Jiang, Y. China's water scarcity. J. Environ. Manag. 2009, 90, 3185-3196. [CrossRef] [PubMed]

37. NL. Factsheet Sponge City Construction in China; Embassy of the Kingdom of the Netherlands, I\&M Department: The Netherlands, 2016; Available online: https://www.nederlandenu.nl/binaries/nl-netherlandsandyou/documenten/publicaties/2016/12/06/2 016-factsheet-sponge-cities-pilot-project-china.pdf/2016-factsheet-sponge-cities-pilot-project-china.pdf (accessed on 8 October 2019).

38. China Meteorological Data. Monthly Average Precipitation Statistics (1981-2010). 2021. Available online: http:/ / data.cma.cn/ data/weatherBk.html (accessed on 14 April 2021).

39. Weather China. Yinzhou Climatic Background. Web Archive. 2012. Available online: https://web.archive.org/web/2012071200 4050/http:/ / www.weather.com.cn/cityintro/101210411.shtml (accessed on 14 April 2021).

40. Repko, A.F.; Szostak, R. Interdisciplinary Research: Process and Theory, 3rd ed.; SAGE: Los Angeles, CA, USA, 2017.

41. He, B.J.; Zhu, J.; Zhao, D.X.; Gou, Z.H.; Qi, J.D.; Wang, J. Co-benefits approach: Opportunities for implementing sponge city and urban heat island mitigation. Land Use Policy 2019, 86, 147-157. [CrossRef]

42. Brown, R.; Farrelly, M.; Keath, N. Summary Report: Perceptions of Institutional Drivers and Barriers to Sustainable Urban Water Management in Australia. Report No 07/06, National Urban Water Governance Program, Monash University. 2007. Available online: https:/ / www.clearwatervic.com.au/user-data/resource-files/NUWGP-Institutional-Drivers-Summary-Report. pdf (accessed on 5 July 2020).

43. Lee, S.; Yigitcanlar, T. Sustainable urban stormwater management: Water sensitive urban design perceptions, drivers and barriers. In Rethinking Sustainable Development: Urban Management, Engineering, and Design; Yigitcanlar, T., Ed.; Premier Reference Source; IGI Global, Engineering Science Reference: Hershey, PA, USA, 2010; pp. 26-37. Available online: https://eprints.qut.edu.au/38 876/ (accessed on 17 May 2020). 